\title{
The Impact of Using Augmented Reality on the Developing the Tenth Graders Motivation Towards Learning: An Applied Study on the Chemistry Courses.
}

\author{
Sabah Jamil Al-Nawaiseh ${ }^{1} \quad$ Ammar M. Al- Nawaiseh $^{2} \quad$ Emad .A.M. Abdalla $^{1}$ \\ 1.Alaqeeq International Schools, Amman .Jordan. \\ 2.International Independent schools, Amman. Jordan.
}

\begin{abstract}
This study aims to reveal the impact of using augmented reality on the motivation towards learning the chemistry curriculum for tenth-grade students. The researchers applied the qusi- experimental approach on a random sample of (49) students divided into two groups; control by (24) students, and experimental by (25) students. The experiment involves the application of augmented reality techniques to explain some of the basic chemistry concepts for the experimental group, and to explain the same concepts by using traditional teaching for the control group. To measure the impact size, amotivation scale has been developed and applied before and after the experiment. The results indicate that there are statistically significant differences in the level of motivation towards learning and acquiring scientific concepts in chemistry according to the method of teaching (augmented, traditional) in favour of the experimental group. In addition, the study recommends the need to adopt the use of augmented reality techniques in teaching chemistry concepts in the basic stages as part of the chemistry teaching standards.
\end{abstract}

Keywords: Augmented Reality; Chemistry; Motivation for Learning.

DOI: $10.7176 / \mathrm{EJBM} / 12-15-13$

Publication date:May $31^{\text {st }} 2020$

\section{Introduction}

The contemporary digital and technological developments have proven their importance in all fields, especially in school and higher education. Information technology and communications allow easy access to information and knowledge available in different forms and multimedia. Consequently, the education system adopts these developments and facilities to be consistent with their features and characteristics to be used in the classroom. Thus, technological applications in education characterized by their ability to create appropriate and supportive conditions for the educational process. It can motivate students by integrating them with advanced educational tools and practices, which in turn creates an innovative and more attractive learning environment by enhancing cooperative work and interaction among learners. The availability of technological tools such as smart devices and their widespread applications allowed the opportunity to make optimal use of those applications in the educational process. This kind of technologies helps to build virtual simulations of reality, which can be used to create an augmented reality that integrates the virtual environment and the real environment. In the context of education, many assistive technologies linked to the concept of augmented reality emerged through smart device applications and the integration of virtual reality during the interducing of educational content.

Virtual reality provides two or three dimensional graphical interface for users interaction and smart devices, in which several graphical applications can be developed as 2D or 3D models, such as interactive and noninteractive game engines, interactive web browsers, 3D simulation and a wide range of other applications (Dahasi, 2017). As for augmented reality, it is the technology in which virtual reality is integrated with real-world environments to make it appear as if the virtual object presented in the real world (Suleiman, 2018); therefore, augmented reality can be combined in various activities and used for different purposes.

In education, especially for science curricula such as chemistry, which address many complex and abstract concepts that the teacher finds difficult to clarify. Hence, augmented reality can greatly help to improve teaching of scientific subjects such as chemistry curriculum, which requires kind of imagination, visualization, and reasoning to understand abstract subjects that are difficult to imagine (Aqel \& Azzam, 2017). The augmented reality technology relies on three-dimensional formation and multimedia, which involve all student's senses to understand scientific concepts, properly perceive them, link them and implement through life examples; and then, improve their motivation and academic level (Al-Saqa \& et al, 2018).

Therefore, this paper aims at revealing the impact of using augmented reality techniques in developing students' motivation to acquire and learn scientific concepts in chemistry for the tenth-graders in Jordan. Students were divided in to two groups: treatment group taking chemistry classes based augmented technology; while control group taking the same classes by using the ordinary way of teaching. Both groups are taking pre and post test in order to investigate the impact of augmented classes. 


\section{Problem Statement and Study Questions}

By reviewing chemistry courses at all school levels, we note the critical need for using some educational and nonordinary tools to ensure that they are clear and understood, as well as improving students' motivation to learn. Therefore, there is a continuous attempt to integrate modern technological development with education. Recently, augmented reality technologies have emerged as non-traditional teaching assistance that helps to boost students' motivation in acquiring scientific concepts; for example, in chemistry as a result of the multiple concepts and abstract symbols. In addition, several studies (Ahmed, 2016; Solak \& Cakir, 2015) showed that the augmented reality applications are more attractive, more productive, and enhance learner motivation through collaborative and participatory education based on integrating virtual reality with the real environment.

However, because of the researcher's work as educators, they noticed a low level of student motivation to learn chemistry, and the inability to retain and retrieve information, especially in topics that need visualization and perception such as chemical bonds. This situation reflected negatively on students 'academic achievement. Accordingly, the problem of the current study can be determined by the low level of students' motivation and the need to motivate them towards learning chemistry using augmented reality and its impact on the level of motivation. Accordingly, the research problem can be addressed through the application of augmented reality technology and revealing its impact on improving learner motivation towards chemistry courses for the tenth-graders in Jordan.

The current study attempts to answer the main question, which states, "What is the impact of using augmented reality technology on improving students' motivation towards learning and acquiring scientific concepts for the tenth-graders in chemistry?". Therefore, the following sub-questions designed:

1 - What is the level of motivation towards learning and acquiring scientific concepts in chemistry for the tenthgraders before applying augmented reality classes?

2- What is the level of motivation towards learning and acquiring scientific concepts in chemistry for the tenthgraders after applying augmented reality classes?

\section{Study hypotheses:}

The current study proposes the following main hypothesis:

"There are no statistically significant differences at the level of $(\alpha<=0.05)$ between students' motivation in the experimental and control groups after the post-measurement towards learning and acquiring scientific concepts in chemistry for tenth -graders."

\section{Aim and Objectives:}

The current study aims to reveal the level of student's motivation towards learning and acquiring scientific concepts in chemistry for tenth -graders. In addition, it detects the impact of the use of augmented reality technology on improving student's motivation towards learning and acquiring scientific concepts in chemistry for tenth -graders.

\section{Study Importance}

The importance of the study lies in handling the use of the most prominent techniques of augmented reality in teaching chemistry, which is characterized by its complex concepts that need assistive methods and models to improve students' motivation to understand relationships, bonds and chemical structures. This, in turn, leads to the practical importance of the study, and supports the use of augmented reality to provide contextual or exploratory education that helps in overcoming a shortage of educational tools and resources, especially as it is possible to exploit the proliferation of smartphones and available applications and use them in the classroom for educational purposes. The concepts, procedures, and results of the study also help researchers to conduct more research and studies related to the application of augmented reality techniques in various subjects, which in turn will provide recommendations to decision-makers to adopt those technological enhancements in the Jordanian school environment.

\section{Study methodology:}

This study uses the qusi-experimental approach-based groups, the control group to be taught by ordinary way, and treatment group to be taught using augmented reality. To measure the impact of using augmented reality on the motivation towards learning basic concepts in the chemistry curriculum for tenth-graders, the researchers measured students' motivation for both groups before starting augmented reality classes. After the completion of augmented reliably classes for the treatment group, the, student's motivation re-measured for both groups in order to verify differences in the level of motivation and determine the potential impact.

\subsection{Study population and sample:}

The population of the study include all male male students of the tenth graders in Amman, The population represented by a sample chosen from Al Aqeeq International School. The sample of the study consisted of 49 
students from the tenth-graders who were randomly divided into two groups, control group composed of (25) students and (24) students of treatment groups.

\subsection{Study Instrument:}

Based on previous studies (Tuan, Chin \& Shieh, 2005; Teetered \& Göke, 2016), the researchers developed the measurement scale for investigating the level of students' motivation toward learning and acquiring scientific concepts in chemistry and pre and posttests for examining the potential impact. In addition, the researchers uses predesigned augmented reality applications based on smartphones to teach the first two units in the chemistry courses for tenth-graders.

\subsection{Validity and reliability of the study:}

To verify the content validity of the motivation scale, the scale was sent to a number of expert arbitrators in curricula and teaching and psychology in Jordanian universities. Their comments were taken to delete, amend, and add some paragraphs to the scale until It was finally approved. Moreover, the construct validity of the scale was tested by analyzing the confirmatory factor that indicated loadings scores for all paragraphs greater $(0.50)$.

To examine the reliability of the scale, in both the pre and post stages, Split-Half method used by splitting the scale paragraphs into two even parts, so that the odd questions are the first part of the scale, and the even questions are the second part. The results the Pearson coefficient between the two parts produced to find the coefficient of the whole scale, which indicated a high and acceptable reliability level ranged from $(80.23-90.23)$.

\section{Literature Review}

Augmented reality is one of the most prominent techniques used in the field of education in the past few years, where it can be said that it is influenced by the constructivist theory in learning, where learners themselves produce knowledge and build meaning accordingly (Wasko \& Polytechnic, 2013,). It can be defined as a type of virtual environment or virtual reality that complements an objective reality but does not completely change it; it allows the learner to see a real-world in which virtual objects are either hypothetical or related to the real world, and the learner through the application of augmented reality can use all of his senses and not only the vision ( McCormack, 2014). Augmented reality enhances the importance of the learner's participation in the learning process, as it enables the presentation and discovery of educational material through its visualization in the real world, since it uses various mediums of scenes, sounds and movements (Klopfer, 2008). Augmented reality technology gives students the opportunity to build new knowledge by interacting with their real world. The more dynamic and interactive the learning experience, the more likely the student will spend more time on the learning process (Boettcher, 2007).

Augmented reality technology also depends on behavioural theory in learning, which focuses on creating an educational situation and providing the learner with stimuli that motivate him to respond and then enhance this response. Therefore, augmented reality seeks to create educational environments in which include multiple media that act as stimuli for learning, and thus enhancing learning and increasing its impact on the learner. Likewise, these techniques can be based on relational theory, which focuses on how learning occurs and not the amount of what has been taught and takes the surrounding environment into consideration. Augmented reality looks at the interaction points within the electronic interaction screens through which virtual objects that enhance the real environment are brought in. Consequently, the learning process with augmented reality takes place through the ability of the learner to effectively access available information to build knowledge and form new scientific concepts (Wasko, \& Polytechnic, 2013).

Chemistry is a complex science due to the use of concepts that cannot be easily understood, and as a result, students have to create images of virtual objects in their imagination; however, not all students are able to create or imagine such visualizations in a way that fits reality, which is an important factor in reducing their motivation towards learning. Consequentially, modern modelling methods using two-and-three-dimensional techniques associated with augmented reality must be used in the teaching chemistry (Nechypurenko \& et al, 2018; Nechypurenko \& eta 1, 2016). The literature on chemistry education provides many studies that show the importance of providing students with a kind of augmented reality and techniques when performing tasks that require the use of thinking skills. Several studies proved that chemistry students who watch the teacher or use augmented reality applications to understand some basic concepts and chemical bonds excel compared with their peers who have not seen or used these applications (Barak, 2013; Booth et al., 2005; Suits \& Sanger, 2013; Williamson et al., 2012).

In another experiment based augmented reality techniques, (Abraham et al, 2010) randomly tested three groups of chemistry students .The first group used two-dimensional paper forms, the second group used twodimensional models supported by augmented reality techniques, and the third group did not use any auxiliary method to examine if there was a difference in their performance in stereoscopic chemistry assessments when compared to a reference group that did not use any models. His results indicated that the students who experienced 
augmented reality models achieved $15 \%$ higher than other groups, and 37\% higher than the reference group in stereoscopic chemistry assessments. In the same experimental context, Aqel \& Azzam, (2017) demonstrated the effectiveness of employing augmented reality in developing the motivation of seventh-grade students and raising their educational achievement in the chemistry topic in the Gaza. They used the (Element 4D) program for augmented reality and indicated the need to employ augmented reality technology in the educational process to suit the Palestinian curriculum.

\section{Results}

This study aimed to reveal the impact of using augmented reality on the motivation towards learning the basic concepts of chemistry curriculum for the tenth-graders. Therefore, this section presents the answers to the study questions and the results of hypothesis testing by answering the study questions and testing the hypotheses. As for answering the main question, which states " What is the impact of using augmented reality technology on improving students' motivation towards learning and acquiring chemical concepts for the tenth-graders? ", we found the arithmetic means and the standard deviations of the two groups' perceptions in the measure of motivation towards learning and acquiring chemical concepts, and the results shown in table (1).

Table 1. Motivation towards learning and acquiring scientific concepts in the pre and posttests

\begin{tabular}{cccccccc}
\hline & Group & Frequency & \multicolumn{2}{c}{ Pre-test } & \multicolumn{2}{c}{ Post-test } \\
\cline { 6 - 8 } Test & & Mean & St.D & Mean & St.D \\
Motivation towards & Treatment & 25 & & 2.66 & .381 & 3.82 & 739 \\
learning and acquiring & Control & 24 & & 2.63 & .586 & 3.00 & .544 \\
scientific concepts & Total & 49 & & 2.64 & .492 & 3.40 & 761 \\
\hline
\end{tabular}

Table (1) shows the existence of apparent differences between the arithmetic means of the tenth graders in the level of motivation towards learning and acquiring scientific chemical concepts in the pre and posttests according to the group. To determine whether the differences between the means are statistically significant at the level of $(\alpha<=0.05)$, ANCOVA test was applied as shown in Table (2).

Table2.ANCOVA of the motivation towards learning and acquiring scientific chemical concepts for pre and posttests.

\begin{tabular}{ccccccc}
\hline Source & Sum of squares & DF & Mean squares & p & Sig & $\begin{array}{c}\text { ( } 2) \text { ETA } \\
\text { square }\end{array}$ \\
\hline Motivation & 7.467 & 1 & 7.467 & 28.190 & .000 & .380 \\
Group & 7.652 & 1 & 7.652 & 28.887 & $.000 *$ & .386 \\
Error & 12.185 & 46 & .265 & & & \\
Adjusted total & 27.813 & 48 & & & & \\
\hline
\end{tabular}

* Statistical significance at the level of $(\alpha<=0.05)$.

Table 2 shows that there are statistically significant differences at the level of $(\alpha<=0.05)$ between the perceptions of the tenth-graders on the scale of motivation towards learning and acquiring scientific chemical concepts according to the method of teaching (augmented or tradition). Therefore, we reject the null hypothesis and accept the alternative, which proposes a significant difference between the tenth-graders scores in the experimental and control groups in the post-measurement of the motivation level towards learning and acquiring scientific concepts in chemistry. To find the impact size, the ETA square was extracted as it reached (0.386), which means that $(38.6 \%)$ of the variance in the motivation level can be attributed to the teaching method. In addition, results in table 3 determine the favour to which group these differences are.

Table 3.Differences between the two groups.

\begin{tabular}{|c|c|c|c|}
\hline Test & Group & $\begin{array}{l}\text { Adjusted } \\
\text { mean }\end{array}$ & $\begin{array}{c}\text { Standard } \\
\text { error }\end{array}$ \\
\hline $\begin{array}{l}\text { Motivation towards learning and acquiring scientific chemical } \\
\text { concepts }\end{array}$ & $\begin{array}{c}\text { Treatment } \\
\text { Control }\end{array}$ & $\begin{array}{l}3.81 \\
3.01\end{array}$ & $\begin{array}{l}.103 \\
.103\end{array}$ \\
\hline
\end{tabular}

Results in Table 3 shows that the Treatment group maintains higher arithmetic mean than the control group in terms of their motivation towards learning chemical concepts.

\section{Discussion for the results:}

Based on the pre and post motivation measurements towards learning chemistry for both control and treatment, augmented reality leads to positive and statistically significant differences between the two groups in the level of students 'motivation towards learning basic concepts and terminologies in chemistry for tenth-graders. This result is attributed to the fact that students in the treatment group have used augmented reality technology to understand these concepts and build a realistic perception, which helps to improve their motivation to learn and to spend more time exploring and analyzing chemical relationships based on those concepts. This supports the goals of the current study and the researcher's perception of the importance of adopting non-ordinary educational methods in teaching 
chemistry in all levels of school education. Moreover, this study is fully consistent with relevant studies (Al-Saqa \& et al, 2018; Nechypurenko, Semerikov \& Tomilina, 2018; Tekedere, H. \& Göke, 2016) related to the need to use augmented reality in teaching chemistry in various education stages due to the nature of chemistry curricula and their need to embody initiative technology.

\section{Recommendations:}

Based on the above results, the study provides the following recommendations:

- The necessity of adopting the use of augmented reality in teaching chemistry for all levels of school education to be a quality standard that must be practised in the classroom.

- Provide the necessary infrastructure in schools to use augmented reality technology.

- More research and studies to our E models for the application of augmented reality in a different detective teaching at the Ministry of Education of Jordan.

\section{References}

1. Wasko, C.,\& Polytechnic, V. (2013). What teachers need to know about augmented reality enhanced learning environments. TechTrends,57(4), 17.

2. Klopfer, E. (2008). Augmented learning: Research and design of mobile educational.

3. arak, M. (2013). Making the Unseen Seen: Integrating 3D Molecular Visualizations in Elementary, High School, and Higher Education. In ACS Symposium Series (Vol. 1142, pp. 273-291).

4. Booth, D., Bateman Jr, R. C., Sirochman, R., Richardson, D. C., Richardson, J. S., Weiner, S. W., ... PutmanEvans, C. (2005). Assessment of Molecular Construction in Undergraduate Biochemistry. Journal of Chemical Education, 82(12), 1854-1858.

5. Suits, J. P., \& Sanger, M. J. (2013). Dynamic Visualizations in Chemistry Courses. In ACS Symposium Series (Vol. 1142, pp. 1-13).

6. Williamson, V. M., Lane, S. M., Gilbreath, T., Tasker, R., Ashkenazi, G., Williamson, K. C., \& Macfarlane, R. D. (2012). The Effect of Viewing Order of Macroscopic and Particulate Visualizations on Students' Particulate Explanations. Journal of Chemical Education, 89(8), 979-987.

7. Abraham, M., Varghese, V., \& Tang, H. (2010). Using molecular representations to aid student understanding of stereochemical concepts. Journal of Chemical Education, 87(12), 1425-1429.

8. McCormack, P. (2014). Augmented Reality. Innovative Education. org.

9. Nechypurenko, P. P., Semerikov, S. O., Selivanova, T. V., \& Shenayeva, T. O. (2016). INFORMATION AND COMMUNICATION TOOLS FOR PUPILS'RESEARCH COMPETENCE FORMATION AT CHEMISTRY PROFILE LEARNING. Information Technologies and Learning Tools, 56(6), 10-29.

10. Nechypurenko, P. P., Semerikov, S. O., \& Tomilina, L. I. (2018). Teoretyko-metodychni zasady vykorystannia informatsiino-komunikatsiinykh tekhnolohii yak zasobu formuvannia doslidnytskykh kompetentnostei starshoklasnykiv u profilnomu navchanni khimii (Theoretical and methodical foundations of using ICT as a tools of forming the senior pupils' research competencies in the chemistry profile learning). Publishing Department of the SIHE "Kryvyi Rih National University”, Kryvyi Rih.

11. Tuan, H. L., Chin, C. C., \& Shieh, S. H. (2005). The development of a questionnaire to measure students' motivation towards science learning. International journal of science education, 27(6), 639-654.

12. Tekedere, H. \& Göke, H. (2016). Examining the Effectiveness of Augmented Reality Applications in Education: A Met Analysis. International Journal of Environmental and Science Education, 11(16), 9469-9481.

13. Al-Saqa, Muhammad Hassan ,Al-Madani, M , Al-Abadleh, Othman, Ahmed, M, and Abu Harb, M. (2018). The effect of augmented reality technology on developing scientific concepts for tenth grade students in biology. Unpublished Master Thesis, Directorate of Education - Khan Yunis - Palestine.

14. Dahasi,J, Ali and Al-Sayed, Hassan,M and Barakat, H. (2017). Using augmented reality technology to develop mathematical thinking skills. Reading and Knowledge Magazine - Egypt, (190), 90-112.

15. Aqel, M, and Azzam, S (2017). The effectiveness of employing augmented reality technology in developing the achievement of seventh grade students in chemistry in the Gaza Strip. International Journal of Learning Management Systems, 6 (1), 27-24.

16. Suleiman, O. (2017). The integration of augmented reality technology in the context of the textbook and its impact on the knowledge impulse and the trend towards it. The Fourth and Fourth International Scientific Conference: Qualitative Education: Present Challenges and Future Visions - Faculty of Specific Education Ain Shams University - Egypt, Volume 3, Cairo: Ain Shams University - Faculty of Specific Education, 860918. 